\title{
Theoretical Investigation of Electronic Structure and Vibrational Spectra of Conformers of Trinitrotoluene and Trinitrophenol
}

\author{
V. KLEIZA ${ }^{a, *}$ AND S. BEKEŠIENE $\dot{E}^{b}$ \\ ${ }^{a}$ Kaunas University of Technology, Klaipėdos str. 1, LT-35209 Panevėžys, Lithuania \\ ${ }^{b}$ Gen. J. Žemaitis Lithuanian Military Academy, Šilo str. 5A, LT-10322 Vilnius, Lithuania
}

\begin{abstract}
The precise knowledge of vibrational spectra would allow detecting small amounts of these materials by means of spectroscopic methods. The results of the investigation of the vibrational spectra of trinitrotoluene and 2,4,6-trinitrophenol molecules were published in our previous paper, where we investigated the normal state of the molecules. In this paper we present the investigation results of the trinitrotoluene and trinitrophenol molecules conformer's with $C_{1}$ and $C s$ symmetry. We analyzed the potential surfaces and vibration spectra by means of $a b$ initio quantum chemical calculations using basis of Gaussian functions and GAMESS package. Calculations were performed at the Hartree-Fock level and with account of the electron correlation. Personal computers clusters necessary for such investigations were made and SCore parallel environment was used.
\end{abstract}

PACS: 31.15.A-, 33.20.Tp

\section{Introduction}

Computational quantum chemistry is the ground of molecular modeling, on prediction the behavior of individual molecules within a chemical system [1]. The basis of molecular modeling investigations is quantum mechanics, but in order to achieve quantitative results and to compare them with the experimental ones we need supercomputer's power or parallel computers cluster. Such way is very useful with explosive materials that require exceptional care in their management [2]. Only few of the 2,4,6-trinitrophenol (TNP) $-\mathrm{C}_{6} \mathrm{H}_{4} \mathrm{~N}_{3} \mathrm{O}_{7}$ (Fig. 1a) molecular structures were examined experimentally. Consequently it is necessary to employ the theoretical methods to find the geometric and electronic structure of these materials to know their properties that help us to create tools for explosive detection. Also for these investigations explosive molecule such as 2,4,6-trinitrotoluene $(\mathrm{TNT})-\mathrm{C}_{7} \mathrm{H}_{5} \mathrm{~N}_{3} \mathrm{O}_{6}$ was chosen (Fig. 1a). The 2,4,6-TNT - the most common nitro aromatic compound used to charge landmines and some of its physical constants, and existing as conformers or different isomers. This work presents the results obtained for the lower energy conformers of 2,4,6-TNT with $C_{1}$ and $C s$ symmetry.

The theoretical investigations of the molecular electronic structure and geometrical data of conformers of 2,4,6-TNP $(C s)$ and 2,4,6-TNT $\left(C_{1}\right.$ and $\left.C s\right)$ were performed applying $a b$ initio quantum mechanical methods using the GAMESS computer code integrated under the SCore type PC cluster TAURAS [3]. The Hartree-Fock

* corresponding author; e-mail: vytautas.kleiza@ktu.lt

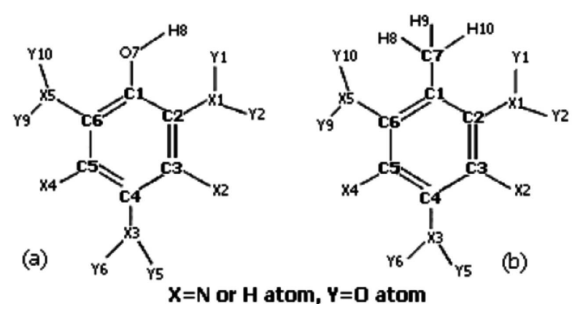

Fig. 1. The molecular structures of explosives: (a) 2,4,6-TNP $-\mathrm{C}_{6} \mathrm{H}_{4} \mathrm{~N}_{3} \mathrm{O}_{7}$; (b) 2,4,6-TNT $-\mathrm{C}_{7} \mathrm{H}_{5} \mathrm{~N}_{3} \mathrm{O}_{6}$. The $\mathrm{X}$ means the nitrogen or hydrogen atoms, $\mathrm{Y}-$ the oxygen atoms.

(HF) and the multiconfigurational self consistent-field (MCSCF) approximations were used for these investigations. Calculated geometrical parameters were compared and found to be in good agreement with the data of X-ray diffraction.

\section{Geometry optimization}

The GAMESS computer code was used as the calculation tool. Calculations for the full geometry optimization was performed for the 2,4,6-TNT molecule with $C s$ and $C_{1}$ symmetry in $\mathrm{HF}$ and in MCSCF approximations, and in the HF approximation for the 2,4,6-TNP molecule with $C s$ symmetry. Theoretical investigations were performed by ab initio quantum mechanical methods using GAMESS computer code in the Linux OS. The structures of investigated molecules are presented with the numbered atoms in Fig. 1. 


\subsection{Geometries of 2,4,6-TNT conformers}

Full geometry optimization was performed for TNT molecule in $\mathrm{HF}$ and in MCSCF approximations. During the investigation the $C_{1}$ and $C s$ symmetry point group of the molecule was assumed. There were calculated all structural parameters (bond lengths, angles, and dihedral angles) of the 2,4,6-TNT conformers. The parameters were obtained with the increase of the basis sets from $6-31 \mathrm{G}^{*}(1 \mathrm{~d})$ to $6-311 \mathrm{G}^{* *}(2 \mathrm{~d}+1 \mathrm{f})$.

TABLE I

Bond lengths of the 2,4,6-TNT ( $C s$ ) calculated and experimental [4].

\begin{tabular}{|c|c|c|c|c|}
\hline \multirow[t]{2}{*}{ Bond $[\AA]$} & \multirow{2}{*}{\begin{tabular}{|c|}
$\mathrm{HF}(C s)$ \\
$6-311 \mathrm{G}^{* *}(2 \mathrm{~d}+1 \mathrm{f})$ \\
\end{tabular}} & \multirow{2}{*}{\begin{tabular}{|c|}
$\operatorname{MCSCF}(C s)$ \\
$6-31 \mathrm{G}^{*}$ \\
\end{tabular}} & \multicolumn{2}{|c|}{ Exp. [4] } \\
\hline & & & Mono & Orto \\
\hline $\mathrm{C} 1-\mathrm{C} 2$ & 1.410 & 1.406 & 1.399 & 1.401 \\
\hline $\mathrm{C} 2-\mathrm{C} 3$ & 1.382 & 1.389 & 1.386 & 1.367 \\
\hline $\mathrm{C} 3-\mathrm{C} 4$ & 1.373 & 1.375 & 1.372 & 1.386 \\
\hline $\mathrm{C} 4-\mathrm{C} 5$ & 1.371 & 1.379 & 1.375 & 1.366 \\
\hline $\mathrm{C} 5-\mathrm{C} 6$ & 1.383 & 1.390 & 1.382 & 1.394 \\
\hline $\mathrm{C} 1-\mathrm{C} 6$ & 1.410 & 1.406 & 1.384 & 1.383 \\
\hline $\mathrm{C} 1-\mathrm{C} 7$ & 1.511 & 1.515 & 1.510 & 1.500 \\
\hline$\langle\mathbf{C C}\rangle$ & 1.406 & 1.409 & 1.401 & 1.400 \\
\hline $\mathrm{C} 7-\mathrm{H} 8$ & 1.080 & 1.080 & 0.989 & 1.002 \\
\hline C7-H9 & 1.080 & 1.080 & 0.985 & 0.914 \\
\hline $\mathrm{C} 7-\mathrm{H} 10$ & 1.080 & 1.080 & 0.898 & 0.918 \\
\hline $\mathrm{C} 3-\mathrm{X} 2$ & 1.068 & 1.067 & 0.978 & 0.933 \\
\hline C5-X4 & 1.068 & 1.066 & 0.967 & 1.029 \\
\hline$\langle\mathbf{C H}\rangle$ & 1.075 & 1.075 & 0.963 & 0.959 \\
\hline $\mathrm{C} 2-\mathrm{X} 1$ & 1.474 & 1.474 & 1.474 & 1.471 \\
\hline $\mathrm{C} 4-\mathrm{X} 3$ & 1.456 & 1.456 & 1.470 & 1.465 \\
\hline $\mathrm{C} 6-\mathrm{X} 5$ & 1.482 & 1.482 & 1.483 & 1.475 \\
\hline$\langle\mathbf{C N}\rangle$ & 1.471 & 1.471 & 1.476 & 1.470 \\
\hline $\mathrm{X} 1-\mathrm{Y} 1$ & 1.191 & 1.205 & 1.228 & 1.219 \\
\hline $\mathrm{X} 1-\mathrm{Y} 2$ & 1.191 & 1.205 & 1.215 & 1.226 \\
\hline $\mathrm{X} 3-\mathrm{Y} 5$ & 1.191 & 1.204 & 1.216 & 1.240 \\
\hline $\mathrm{X} 3-\mathrm{Y} 6$ & 1.191 & 1.204 & 1.212 & 1.210 \\
\hline $\mathrm{X} 5-\mathrm{Y} 9$ & 1.191 & 1.205 & 1.215 & 1.240 \\
\hline $\mathrm{X} 5-\mathrm{Y} 10$ & 1.191 & 1.205 & 1.208 & 1.117 \\
\hline$\langle\mathrm{NO}\rangle$ & 1.191 & 1.205 & 1.216 & 1.218 \\
\hline Energy & -881.432 & -881.491 & - & - \\
\hline
\end{tabular}

Table I shows the HF and MCSCF calculated bond lengths of the $C s$ conformer and the value of bond lengths obtained experimentally for the orthorhombic and monoclinic crystal structure of TNT [4]. The bond lengths for $C s$ conformers in both methods were in good agreement with the experimental result, except the $\mathrm{C}-\mathrm{H}$ bond lengths that were overestimated by about $11 \%$. The $\mathrm{HF} / 6-311 \mathrm{G}^{* *}(2 \mathrm{~d}+1 \mathrm{f})$ calculations for all the $\mathrm{N}-\mathrm{O}$ bond lengths were within $2 \%$ of the experimental result by experimental values for both crystal structures.
The MCSCF $/ 6-31 \mathrm{G}^{*}$ calculations for all the $\mathrm{N}-\mathrm{O}$ bond lengths were within $1 \%$ of the experimental result.

The 2,4,6-TNT conformer with the $C_{1}$ symmetry optimization was performed using $\mathrm{HF}$ and MCSCF approximations. The theoretical prediction of the bond lengths for $C_{1}$ conformers in both methods and all basis sets were within $1.5 \%$ of the experimental result, except the $\mathrm{C}-\mathrm{H}$ bond lengths that were overestimated by 2.0 to $16 \%$. The MCSCF calculations showed that all the $\mathrm{N}-\mathrm{O}$ bond lengths were within about $1-1.5 \%$ of the experimental result.

The atoms labeling in the tables are consistent with the labeling model shown in Fig. 1. The optimized geometries for the TNT conformers with $C s$ and $C_{1}$ symmetry have showed different deformations of the phenyl ring and distortions of the internal rotation of the nitro and methyl groups.

The energy calculations obtained using different methods with the family of basis sets from the $6-31 \mathrm{G}^{*}(1 \mathrm{~d})$ to $6-311 \mathrm{G}^{* *}(2 \mathrm{~d}+1 \mathrm{f})$ for the two conformers $\left(C s\right.$ and $\left.C_{1}\right)$ indicate that the $C s$ conformer is lower in energy than the $C_{1}$ conformer. The stability of $C s$ structures is also confirmed by other scientists [4].

\subsection{Calculation results for 2,4,6-TNP}

The molecular structure of 2,4,6-TNP molecule are shown in Fig. 1. The geometrical values of this molecule were optimized. The obtained data are shown in Table II. The labeling of the atoms is consistent with the labeling model shown in Fig. 1. The obtained calculating results are compared with the experimental data $[5,6]$. The $C s-C_{1}$ bonds are dominated by the resonance and inductive effects. The bond lengths calculated by the $\mathrm{HF} / 6-31 \mathrm{G}^{*}$ method are close to the experimental values and calculation tends to give shorted bonds than the experimental data for the $\mathrm{C}-\mathrm{NO}_{2}$ bonds [6].

Through geometrical optimization and the second derivative examination the bond lengths, bond angles, dihedral angles, dipole moment and energy were calculated. The negative vibrational frequency showed that 2,4,6-TNP $(C s)$ molecule is a transition state structure. There is a significant difference in all dihedral angles between the transition state structure and the "normal" structure. No matter which calculation method is used, the results show that hydrogen bounds are similar to those obtained from the experimental data.

\section{Vibrational spectra calculations}

Vibrational frequencies were estimated for the two lower-energy conformers through theoretical analysis. Vibrational frequencies and IR intensities were calculated using $\mathrm{HF}$ approximation with the family of basis sets from $6-31 \mathrm{G}^{*}(1 \mathrm{~d})$ to $6-311 \mathrm{G}^{* *}(2 \mathrm{~d}+1 \mathrm{f})$ and $\mathrm{MCSCF} /$ 6-31G*, for the $C s$ and $C_{1}$ conformers. The calculated frequencies were compared with the experimental frequencies obtained from a TNT crystal in Table III. 
TABLE II

The 2,4,6-TNP $(C s)$ molecule dihedral angles $\left({ }^{\circ}\right.$ ), dipole moments (Debye), energies (Hartree) calculated in the HF approximation in the $6-31 G^{*}$ basis set on cluster TAURAS and by Chen, also experimental values $[5,6]$.

\begin{tabular}{c|c|c|c|c}
\hline \hline Dihedral angles [ $\left.{ }^{\circ}\right]$ & $\begin{array}{c}\mathrm{HF} / 6-31 \mathrm{G}^{*} \\
\text { (normal) [5] }\end{array}$ & $\begin{array}{c}\mathrm{HF} / 6-31 \mathrm{G}^{*} \\
\text { (transition state) [5] }\end{array}$ & Exp. [6] & $\begin{array}{c}\mathrm{HF} / 6-31 \mathrm{G}^{*} \\
\text { (transition state) }\end{array}$ \\
\hline O7-C1-C6-C2 & -176.5 & 180.0 & - & 180.0 \\
H8-O7-C1-C2 & 0.7 & 0.0 & - & 0.0 \\
X1-C2-C1-C3 & 0.3 & 180.0 & 7.4 & 180.0 \\
Y1-X1-C2-C1 & 1.7 & 0.0 & - & 0.0 \\
X2-C3-C2-C1 & 180.0 & 180.0 & - & 180.0 \\
X3-C4-C3-C2 & -179.7 & 180.0 & 0.6 & 180.0 \\
Y5-X3-C4-C3 & 0.4 & 0.0 & - & 0.0 \\
X4-C5-C4-C3 & 180.0 & 180.0 & - & 180.0 \\
X5-C6-C5-C1 & 177.8 & 180.0 & 17.2 & 180.0 \\
Y9-X5-C6-C5 & 34.4 & 0.0 & - & 0.0 \\
\hline dipole moment & 1.84 & 2.02 & - & -916.08196 \\
energy & -915.94982 & -915.94861 & &
\end{tabular}

TABLE III

The most significant intensities of IR vibrational frequencies (forms) calculated in the MCSCF approximation in the 6-31G* basis for TNT conformers $\left(C_{1}\right.$ and $\left.C s\right)$ and experimental results [4].

\begin{tabular}{|c|c|c|c|c|c|}
\hline $\begin{array}{l}C s \\
\text { freq. }\left[\mathrm{cm}^{-1}\right]\end{array}$ & $\begin{array}{l}\text { IR } \\
\text { int. }\end{array}$ & $\begin{array}{c}\quad C_{1} \\
\text { freq. }\left[\mathrm{cm}^{-1}\right]\end{array}$ & IR int. & $\begin{array}{c}\text { IR } \\
\text { exp. }[4]\end{array}$ & Vibration form \\
\hline 1229 & 11 & 1231 & 9 & 1200 & $\begin{array}{l}\mathrm{NO}_{2}, \mathrm{CN} \text { bond stretching and benzene ring } \\
\text { in the molecule plane deformations }\end{array}$ \\
\hline 1402 & 338 & 1390 & 340 & 1350 & $\begin{array}{l}\mathrm{NO}_{2}, \mathrm{CN} \text { bond stretching and benzene ring } \\
\text { in the molecule plane deformations }\end{array}$ \\
\hline 1590 & 199 & 1599 & 186 & 1533 & $\mathrm{NO}_{2}$, benzene ring deformations \\
\hline 1601 & 371 & 1605 & 133 & 1545 & $\begin{array}{l}\mathrm{NO}_{2}, \mathrm{CN} \text { bond stretching and benzene ring } \\
\text { in the molecule plane deformations }\end{array}$ \\
\hline 1624 & 14 & 1638 & 323 & 1551 & $\begin{array}{l}\mathrm{NO}_{2}, \mathrm{CN} \text { bond stretching and benzene ring } \\
\text { in the molecule plane deformations }\end{array}$ \\
\hline 1666 & 140 & 1651 & 89 & 1617 & $\begin{array}{l}\mathrm{NO}_{2} \text {, benzene ring in the molecule plane } \\
\text { deformations }\end{array}$ \\
\hline 3066 & 1 & 3060 & 5 & 2882 & $\mathrm{CH}_{3}$ group stretching vibrations \\
\hline 3115 & 3 & 3122 & 7 & 2919 & $\mathrm{CH}_{3}$ group stretching vibrations \\
\hline 3157 & 4 & 3172 & 3 & 2956 & $\mathrm{CH}_{3}$ group stretching vibrations \\
\hline 3267 & 30 & 3267 & 22 & 3098 & $\mathrm{CH}$ and $\mathrm{CH}_{3}$ valence angle deformations \\
\hline
\end{tabular}

We observed a small difference between the symmetric and the asymmetric frequencies value as well as the differences in the vibrational mode of the nitro group for $C s$ and $C_{1}$ conformers of TNT. The MCSCF $/ 6-31^{*}$ level of theory appears to give the good imitation of the experimental spectra. The theoretical spectra help us to assign the vibrations bands of the experimental ones. Figure 2 shows a comparison of the calculated infrared spectra performed with MCSCF approximation using the $6-31 \mathrm{G}^{*}$ basis sets, for the two 2,4,6-TNT conformers $\left(C s, C_{1}\right)$ and also the experimental data. The visualization of the calculation results, achieved by the cluster, was done by the MOLDEN application program.

We found that the spectra of the two conformers, in the region below $1250 \mathrm{~cm}^{-1}$, do not change significantly when the basis set was varied. On the other hand, a noticeable change was in the region above $1250 \mathrm{~cm}^{-1}$ when we vary the basis sets. In this region we twigged a shift in the nitro group, the phenyl ring and the methyl group bands. 

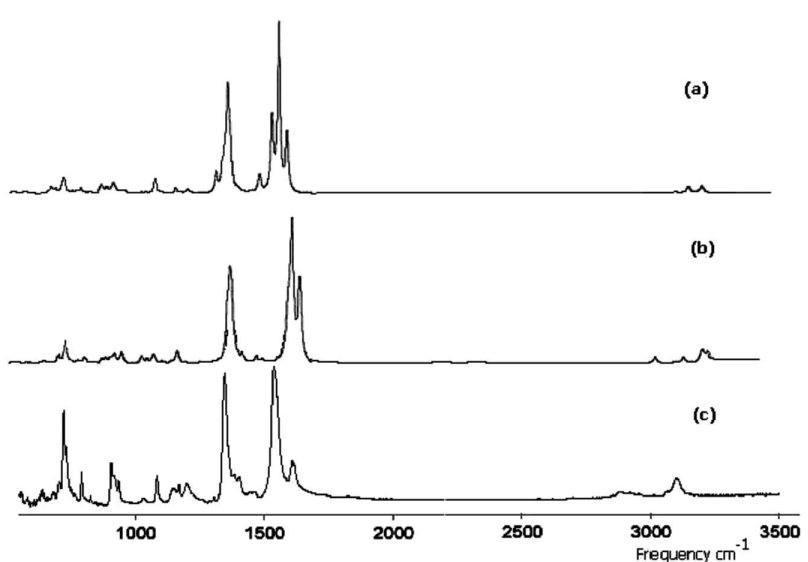

Fig. 2. Experimental (c) infrared spectrum of neat $2,4,6-$ TNT in range of $500-3500 \mathrm{~cm}^{-1}$ and calculated IR vibrations of 2,4,6-TNT conformers in the MCSCF / 6-31G*: (a) Cs symmetry; (b) $C_{1}$ symmetry.

The frequency shifts in the symmetric nitro group were in the range $1402-1425 \mathrm{~cm}^{-1}$ for $6-31 \mathrm{G}^{*}$ and in the range $1310-1390 \mathrm{~cm}^{-1}$ for $6-311 \mathrm{G}^{* *}$ basis set. The shifts in frequency for the asymmetric nitro group were in the range $1620-1680 \mathrm{~cm}^{-1}$ for $6-31 \mathrm{G}^{*}$ and for the range $1565-1630 \mathrm{~cm}^{-1}$ for $6-311 \mathrm{G}^{* *}$ basis sets. The shifts for the phenyl ring deformation were in the range $1680-1710 \mathrm{~cm}^{-1}$ for $6-31 \mathrm{G}^{*}$ and for $1630-1680 \mathrm{~cm}^{-1}$ for $6-311 \mathrm{G}^{* *}$ basis sets. The methyl group shifts of vibrational frequencies were in the range $3250-3350 \mathrm{~cm}^{-1}$ for $6-31 \mathrm{G}^{*}$ and $6-311 \mathrm{G}^{* *}$ basis sets.

The vibrational bands for the two conformations $\left(C s, C_{1}\right)$ were very similar only if the changes in the vibrational mode of the methyl and nitro group frequencies were detected. The found differences in the vibrational bands might be assigned to the variation in the structure of the two conformers as well as the dissimilar contributions of the nitro and methyl group to the normal mode.

\section{Conclusions}

The results of this study provide valuable information in the field of aromatic nitro compounds and let us foresee that cluster TAURAS allows solving the modern quantum chemical problems at necessary HF level.

Therefore, the calculations of 2,4,6-TNT conformers by MCSCF method showed significant change of the vibrational spectrum characteristics from those calculated at HF level. Achieved results with the increasing calculations can help us better understand on what depend the benzene ring and $\mathrm{NO}_{2}$ group deformations, the frequencies of $\mathrm{NO}_{2}$ group and $\mathrm{CH}$ bonds stretching vibrations.

The performed theoretical analysis of the molecular structures of conformers allow one evaluate the stability of these molecules. The energy calculations obtained using the different methods with the family of basis sets for the two TNT conformers $\left(C s\right.$ and $C_{1}$ ) indicate that the $C s$ conformer is lower in energy than the $C_{1}$ conformer.

\section{References}

[1] S. Bekesienè, V. Kleiza, J. Tamuliene, in: Proc. 3rd Int. Workshop ITELMS'2008, Eds. Z. Bazaras, V. Kleiza, Panevezys (Lithuania) 2008, p. 7.

[2] M.W. Schmidt, K.K. Baldridge, J.A. Boatz, S.T. Elbert, M.S. Gordon, J.H. Jensen, S. Koseki, N. Matsunaga, K.A. Nguyen, S. Su, T.L. Windus, M. Dupuis, J.A. Montgomery Jr, J. Comput. Chem. 14, 1347 (1993).

[3] Y. Ishikawa, H. Tezuka, A. Hori, S. Sumimoto, T. Takahashi, F. O'Carroll, H. Harada, in: Proc. 5th Annual Linux Expo, 1999, p. 55.

[4] N.I. Golovina, A.N. Titkov, A.V. Raevskii, L.O. Atovmyan, J. Solid State Chem. 113, 229 (1994).

[5] P.C. Chen, S.C. Tzeng, J. Mol. Struct. (Theochem) 467, 243 (1999).

[6] E.N. Duesler, J.H. Engelmann, D.Y. Curtin, I.C. Paul, Cryst. Struct. Commun. 7, 449 (1978). 